\title{
Analysis of Unsteady Behaviour of Natural Circulation Helium Loop
}

\author{
Matej Vach ${ }^{1, *}$, Branislav Knížat ${ }^{1}$, Marek Mlkvik ${ }^{1}$, Róbert Olšiak ${ }^{1}$, František Urban ${ }^{1}$, \\ František Ridzoñ ${ }^{1}$, and Peter Mlynár ${ }^{1}$ \\ ${ }^{1} \mathrm{SjF}$ STU in Bratislava, Institute of Energy Machinery, 81107 Bratislava, Slovakia
}

\begin{abstract}
This paper deals with the one-dimensional unsteady fluid flow model of the natural circulation loop. The presented model represents the experimental facility Helium Loop STU which is the physical model of an emergency coolant system of a nuclear reactor. The governing equations are solved according both Euler and Lagrange approaches on two parallel computational grids. Linearization of equations and semi-implicit discretization scheme are used to enhance the algorithm effectiveness. The simulation results were compared to experimental data. The model can be considered as high-accurate in comparison with experimental data (relative error $1.14 \div 1.15 \%$ at specified time interval).
\end{abstract}

\section{Introduction}

The natural convection loops, also called thermosyphons, are specific type of thermohydraulic circuits. They are fully autonomous and electricity-free by their nature. This significant benefit leads to a large number of possible applications in a variety of fields. They can be used for cooling (small electronic devices [1], gas turbine blades $[2], \ldots$ ), heating (oil baths $[3], \ldots$ ) or in solar collector systems. However, the most crucial application is the emergency cooling of a nuclear reactor.

The experimental facility Helium Loop STU is a part of the ALLEGRO project which contributes to the $4^{\text {th }}$ Generation Nuclear Reactor Systems development. The physical model (Helium Loop STU) represents the emergency coolant system of the nuclear core. It belongs to the passive safety systems family thanks to the electricity-free operation which enhances the system reliability.

The principle of a thermosyphon is based on the thermal differential along the thermohydraulic circuit. Typically, the flowing medium is heated at the bottom and cooled at the top of the apparatus which results in the fluid motion. Nevertheless, the fluid flow behaviour is highly dependent on operational conditions, especially the heat fluxes in and out of the system (heating and cooling). Improper conditions can lead to flow instabilities and reversals.

\footnotetext{
*Corresponding author: matej.vach@stuba.sk
} 


\section{Physical model}

The experimental facility was built in Trnava and is shown in Fig. 1.

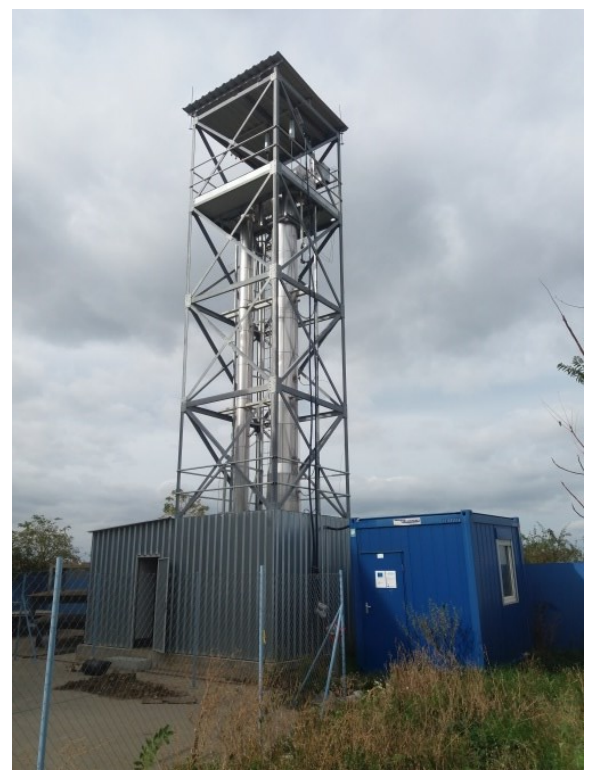

Fig. 1. The Helium Loop STU in Trnava.

The nuclear core is represented by the electric heater with installed power input of $500 \mathrm{~kW}$. The operational pressure is within the range $3 \div 7 \mathrm{MPa}$ and the temperature $150 \div 520{ }^{\circ} \mathrm{C}$. The cooler cooling capacity is $220 \mathrm{~kW}$. The main dimensions are shown in Table 1 .

Table 1. Helium Loop STU main dimensions.

\begin{tabular}{|c|c|}
\hline dimension $(\mathrm{mm})$ & value $(\mathrm{mm})$ \\
\hline height & 9994 \\
\hline width & 1347 \\
\hline $\begin{array}{c}\text { internal pipe } \\
\text { diameter }\end{array}$ & 168.3 \\
\hline
\end{tabular}

There are several types of measuring devices arranged along the thermohydraulic circuit. Measured parameters are: temperature, pressure, velocity, $\mathrm{H}_{2} \mathrm{O}$ mass flow rate (in the cooler) and the heater power input. The complex experimental facility is fully described in the technical report [4]. 


\section{Mathematical model}

\subsection{Governing equations}

The thermohydraulic circuit consists from four main parts: the heater, the cooler, the hot branch (pipe segment) and the cold branch (pipe segment) as shown in

Fig. 2.

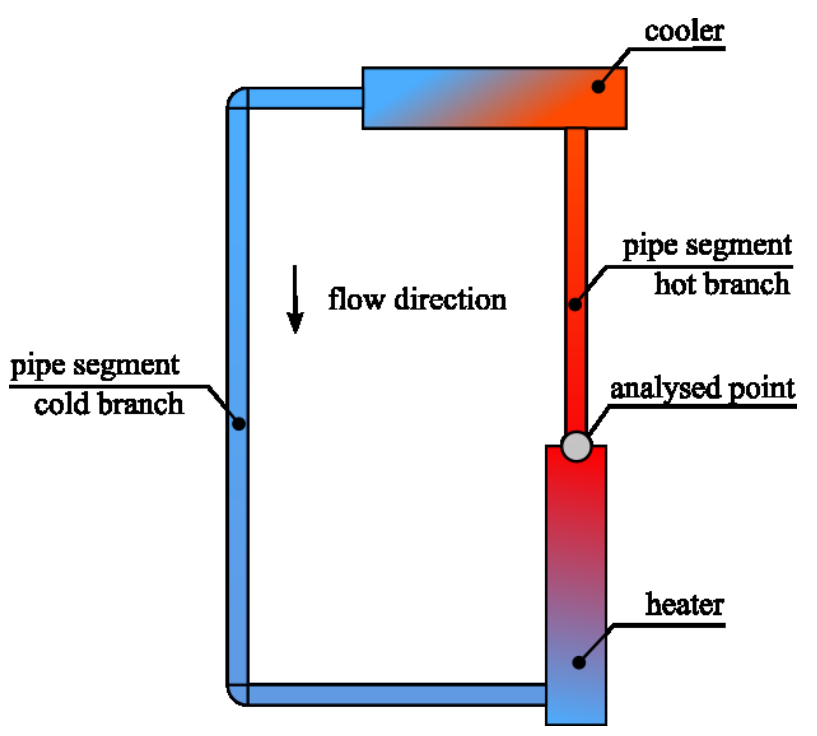

Fig. 2. The Helium Loop STU base scheme.

The one-dimensional fluid flow can be described by three governing equations conservations of mass (1), momentum (2) and energy (3). The equation system is completed by the real gas equation of state (4) where coefficient of compressibility $z$ is calculated according the Soave-Redlich-Kwong real gas equation of state.

$$
\begin{gathered}
\frac{\partial(p / z)}{\partial t}+\frac{r T}{A} \frac{\partial Q_{m}}{\partial x}=0 \\
\frac{\partial Q_{m}}{\partial t}+\frac{A g p}{z r T} \frac{\mathrm{d} h}{\mathrm{~d} x}+\frac{r T}{A} \frac{\partial\left[z Q_{m}^{2} / p\right]}{\partial x}+A \frac{\partial p}{\partial x}+\lambda \frac{z r T}{2 d A} \frac{\left|Q_{m}\right| Q_{m}}{p}=0 \\
\mathrm{~d} i=\mathrm{d}(u+p / \rho)=c_{p} \mathrm{~d} T-c_{p} k_{J T} \mathrm{~d} p \\
p=\text { ń } z r T
\end{gathered}
$$

Signs used: $p$ - pressure, $Q_{m}$ - mass flow rate, $T$ - temperature, $\rho$ - density, $A$ - area of cross-section of a pipe, $\lambda$ - Darcy-Weisbach head loss coefficient, $r$ - specific gas constant, $g$ - gravity acceleration, $t$ - time, $x$ - space coordinate, $h$ - height, $d$ - internal diameter of a pipe, $c_{p}$ - specific heat capacity, $k_{J T}$ - Joule-Thomson coefficient, $i-$ specific enthalpy and $u$ - specific internal energy. 
The equation of state was chosen according the results of the paper [5]. The first (1) and second (2) formulas were solved according to Euler approach and the third conservation law (3) according to Lagrange approach.

\subsection{Models of main parts of the Helium Loop STU}

The estimation of minor losses in pipe segments is based on assumption of hydraulically smooth pipes. Then the coefficients are evaluated according Blasius and Herman formulas (depending on the flow regime). The simulation of heat loss through the pipe wall is based on the temperature of environment and the heat flux coefficient of air.

The primary sources of the energy input and output are the heater and cooler models. Both of them include the enhanced energy equation where the energy fluxes and heat accumulation are modelled. The heat flux inside the cooler is evaluated according standard NTU-epsilon method. The heat flux coefficients are determined using the Bell-Delaware method. The heat accumulation is evaluated according to the material properties of the heat exchanger object. The energy output is moderated by $\mathrm{H}_{2} \mathrm{O}$ mass flow rate and temperature which are set as boundary conditions. The energy input - through the heater - is also set as a boundary condition thus the value is known (electric power input). The minor loss coefficients are set as constants (according results in the paper [6]).

The mass leakage is set as the boundary condition which value is based on the experimental data approximation [6].

\subsection{Numerical implementation}

The combination of Euler and Lagrange approaches resulted in the use of two parallel computational grids - the fixed and the floating grid. The governing equations (1) (2) are discretized on the fixed grid using the semi-implicit scheme as described in paper [7]. The semi-implicit time marching is based on integrating the time derivation according to equation (5) where the right side of the equation $X_{j-\theta}$ is written as (6). The semi-implicit parameter $\vartheta$ represents the ratio of explicit to implicit terms in equations, where the $\vartheta$ value lies inside interval from 0 to $1(\vartheta=0$ means fully implicit and $\vartheta=1$ fully explicit formulation).

$$
\begin{gathered}
\left(\frac{\mathrm{d} y}{\mathrm{~d} t}\right)_{j-\vartheta}=(1-\vartheta) X_{j}+\vartheta X_{j-1} \\
X_{j-\vartheta}=(1-\vartheta) \cdot X_{j}+\vartheta \cdot X_{j-1}
\end{gathered}
$$

However, the solution procedure of one time-step includes several interpolations between grids which have their roots in the calculation of the mass flow rate and the pressure in the fixed grid nodes and the temperature in the floating grid nodes. The temperature is calculated according to equation (7) which stems from the solution of the differential equation (3).

$$
T_{j+1}=T_{e x t}+\left(T_{j}-T_{e x t}\right) \exp \left(-\frac{4 D_{e} k \Delta t}{d^{2} \rho c_{p}}\right)-k_{J T}\left(p_{j}-p_{j+1}\right)
$$

The term $k$ represents the coefficient of heat flux through the pipe wall, $T_{\text {ext }}$ is the environment temperature and the external diameter is $D_{e}$.

The method suitability for the thermosyphon simulation was confirmed by authors [7]. The system of equations (1) - (3) is nonlinear by its nature and therefor was converted into the linear system which can be described by sparse matrixes. Thus the solution can be 
obtained by a rapid direct technique (e.g. LU factorisation) [8], [9]. The numerical implementation of the complex model was performed using the $\mathrm{C} / \mathrm{C}++$ programing language.

\section{Results}

The simulations were performed for two scenarios which were based on two measurements. The initial conditions can be viewed in Table 2 . The boundary conditions $\left(\mathrm{H}_{2} \mathrm{O}\right.$ mass flow rate and temperature in DHR, the electric power input in GFR, He mass leakage and $T_{\text {ext }}$ ) were set according the measurement scenarios.

Table 2. Initial conditions.

\begin{tabular}{|c|c|c|}
\hline parameter & Scenario 1 & Scenario 2 \\
\hline$p_{H e}(\mathrm{~Pa})$ & 2504274 & 953846 \\
\hline$T_{H e}\left({ }^{\circ} \mathrm{C}\right)$ & 46.6 & 23.1 \\
\hline$Q_{m}\left(\mathrm{~kg} \cdot \mathrm{s}^{-1}\right)$ & 0.0 & 0.0 \\
\hline
\end{tabular}

The comparison between simulated and experimental data was performed. The temperature at a specific point was compared. The point of interest is illustrated in Figure 2 and the results can be seen in Figure 3.

The relative error of temperature was evaluated and averaged at chosen time interval 15 min before device shutdown. This value approximately matches the interval closest to the steady state flow regime. Values of errors and corresponding time intervals are shown in Table 3.

Table 3. Results: relative error of temperature.

\begin{tabular}{|c|c|c|}
\hline parameter & Scenario 1 & Scenario 2 \\
\hline $\begin{array}{c}\text { Investigated time } \\
\text { interval }(\mathrm{h}: \mathrm{min}: \mathrm{s})\end{array}$ & $4: 32: 1 \div 4: 47: 1$ & $3: 38: 26 \div 3: 53: 26$ \\
\hline$T_{\text {He, err, ave }}(\%)$ & 1.15 & 1.14 \\
\hline
\end{tabular}




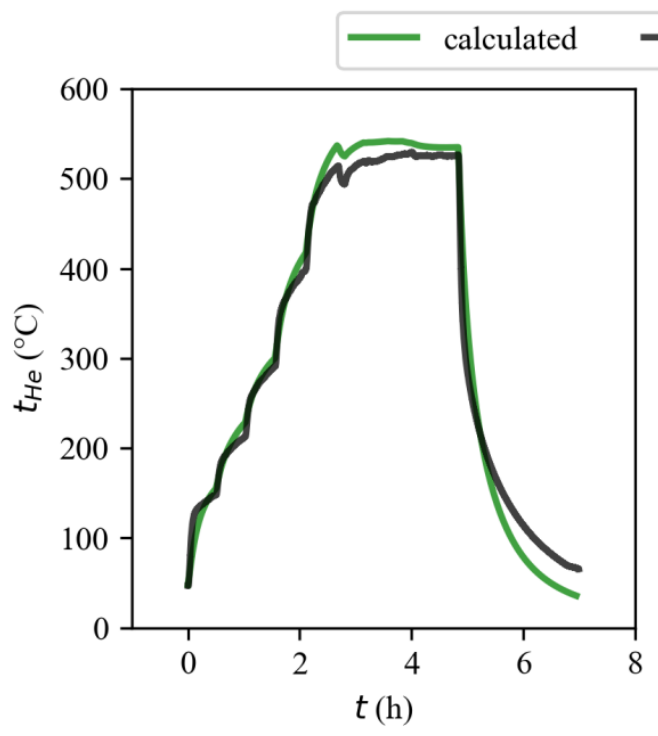

(a)

\section{experimental}

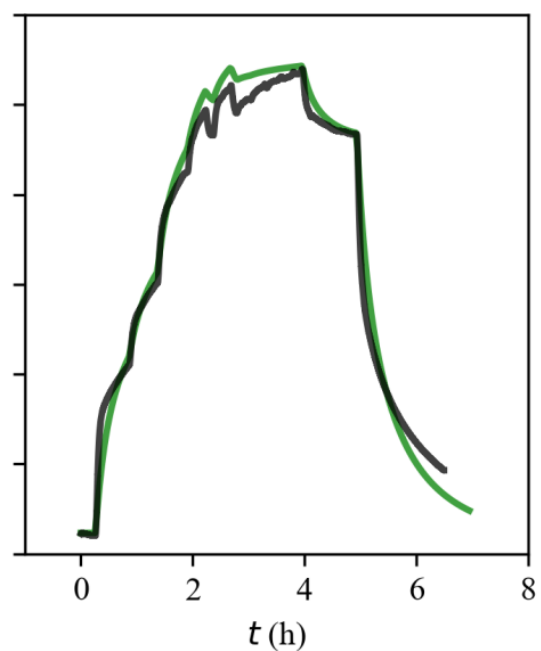

(b)

Fig. 3. The comparison between calculated and experimental data : (a) - temperature at the point of interest for scenario $1 ;(b)$ - temperature at the point of interest for scenario 2.

\section{Conclusion}

The complex model of the transient Helium Loop STU model was presented. Description of the mathematical and physical models was provided. The mathematical model was numerically implemented and simulation of two scenarios was performed. The results were compared to the experimental data and show that the model is relatively accurate $(1.15 \%$ and $1.14 \%$, see Table 3 ) and can be used to model the thermosyphon flow behaviour.

However, the error rate arises during highly unsteady flow, see Figure 3. The deviation could have its roots in several simplifications of the model (e.g. one-dimensional flow, constant minor loss coefficients in heat exchangers, unsteady heat flux through pipe wall due to current wind velocity etc.). Furthermore, there is a high chance that the physical model flow includes backflows and swirls as mentioned in the article [5]. Thus the modelled heat accumulation (in solid parts of both the heater and the cooler) is also simplified - the real heat accumulation is probably more complex and nonlinear. The neglected heat accumulation in solid parts of pipe segments can also be the source of deviations.

This paper presents the complex unsteady model of the natural convection loop. The results show that the model is capable of simulating the transient flow behaviour and can be a strong foundation for passive safety nuclear core cooling system development. 
Acknowledgement

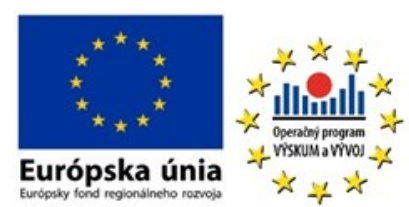

This contribution was created on the basis of the project "Research centre ALLEGRO" (ITMS project code: 26220220198), supported by Operational Programme Research and Development funded by the European Regional Development Fund.

The authors gratefully acknowledge the contribution of the Scientific Grant Agency of the Slovak Republic under the grant VEGA 1/0743/18.

\section{References}

1. H. Cohen and F. J. Bayley, Heat transfer problems of liquid cooled gas turbine blades, Proc. Inst. Mech. Eng., 169, pp. 1063-1080, (1955)

2. Y. Cao and M. Gao, Wickless network heat pipes for high heat flux spreading applications, Int. J. Heat Mass Transf., 45, pp. 2539-2547, (2020)

3. C. C. Vincent and J. B. W. Kok, Investigation of the overall transient performance of the industrial two-phase closed loop thermosyphon, Int. J. Heat Mass Transf., 35, pp. 1419-1426, (1992)

4. F. Urban, P. Élesztos, R. Palenčár, Š. Emmer, K. Jelemenský, B. Knížat and L'. Kolláth, Research report for research center Allegro, (STU in Bratislava, 2016)

5. F. Világi, B. Knížat, F. Urban, R. Olšiak, M. Mlkvik, F. Ridzoň and P. Mlynár, Estimation of minor losses in a natural circulation helium loop, Engineering mechanics, pp. 1030-1033, (2017)

6. F. Világi, B. Knížat, M. Mlkvik, F. Urban, R. Olšiak, P. Mlynár and F. Ridzoň, Measurement of leakages in a helium loop, AIP, 2118 (2019)

7. M. Vach, B. Knížat and P. Mlynár, Analysis of Numerical Methods Suitable for 1D Simulation of Thermosyphons, AIP, 2118 (2019)

8. J. Králik, P. Stieger, Z. Vostrý and J. Závorka, Dynamic Modeling of Large-scale Networks with Application to Gas Distribution (Elsevier Science Ltd, Amsterdam, 1988), pp. 196-201

9. J. D. Anderson, Computational Fluid Dynamics » Basics with Applications (MsGrawHill, New York, 1995), pp. 152-153 